\title{
RANCANG BANGUN ULANG MESIN PENCETAK MIE
}

\author{
Angga Maulana Hidayatulloh \\ Teknik Mesin, Fakultas Teknik \\ Universitas Maarif Hasyim Latif, Sidoarjo, Indonesia \\ e-mail : anggamaulana158@gmail.com
}

\begin{abstract}
ABSTRAK
Mie dapat di katagorikan sebagai salah satu komoditi pangan subtitusi karena dapat berfungsi sebagai bahan pangan pokok. Dengan banyaknya permintaan pasar akan penggunaan mie sehingga dibutuhkan mesin pencetak mie pasta dengan kapasitasn $1 \mathrm{Kg} /$ menit. Perencanaan mesin pencetak mie ini dapat memperoleh ketelitian dan kelayakan sesuai dengan kapasitas yang diinginkan. Perencanaan mesin pencetak mie dengan system screw horizontal dengan sepesifikasi sebagai berikut, Daya motor : $0.37 \mathrm{Kw}$, $1500 \mathrm{Rpm}$. Transmisi yang digunakan, yaitu dari motor listrik ditransmisikan pada puli dengan diameter puli 1 berukuran $21 \mathrm{~mm}$, Puli 2 berukuran $42 \mathrm{~mm}$, Puli 3 berukuran $45 \mathrm{~mm}$. Poros yang digunakan dari bahan stainless berdiameter $30 \mathrm{~mm}$. Bahan pengaduk mixer menggunakan stainlees agar tahan korosi. Bahan screw menggunakan teflon agar adonan tetap memenuhi standart makanan. Body menggunakan bahan stainlees agar tahan korosi dan memenuhi standart.
\end{abstract}

Kata kunci: Mesin Pencetak Mie, Motor Listrik, Pengaduk Mixer, Puli, System Screw Horizontal, Stainless

\section{PENDAHULUAN}

Mie merupakan pilihan makanan pokok kedua setelah nasi di Indonesia. Bahkan menurut data World Instant Noodles Association (WINA), penjualan mie instant di Indonesia pada tahun 2015 mencapai 14,4 miliar bungkus dibawah Cina sebesar 42,3 miliar bungkus dan hal ini menjadikan Indonesia sebagai Negara kedua di dunia dalam mengkonsumsi mie terbanyak setelah china. (Tabloid Pasar,2015:1).

Namun pada umumnya pembuatan mie ditingkat pedagang masih menggunakan cara manual yaitu dengan menggunakan tenaga manusia dalam proses produksinya. Hal ini kurang efisien mengingat lama waktu yang digunakan untuk membuat adonan mie menjadi pulen dan berbentuk kecil. Waktu yang cukup lama untuk memproduksi mie secara manual telah menimbulkan problematika sehingga produksi mie dalam sehari tidak dapat ditingkatkan dan tidak dapat mengimbangi kebutuhan pasar yang cukup besar serta menimbulkan ketidak seimbangan antara kapasitas produksi dan permintaan pasar yang menuntut beberapa pedagang berinisiatif untuk memproduksi mie sendiri dengan alat seadanya. Penggunaan teknologi telah merambah diberbagai sektor kehidupan termasuk dalam sektor produksi makanan. Salah satu contoh penggunaan teknologi dalam sektor tersebut adalah industri pembuatan mie yang memanfaatkan mesin produksi pemipih dan pemotong adonan mie agar proses produksi lebih efisien. Namun mesin produksi mie yang saat ini digunakan dengan proses pemipih dan pemotong adonan mie masih kurang efisien.
Berdasarkan dari hal tersebut diatas peneliti ingin mengetahui sistem rancang bangun suatu alat untuk memberikan solusi agar proses pembuatan mie lebih mudah dan cepat.

\section{METODE PENELITIAN}

Mesin pencetak mie adalah mesin dengan gerak utama berputar. Gaya putar ini disebabkan karena putaran dari motor listrik. Motor listrik dipasang disamping body karena ukuran mesin yang cukup besar sehingga tidak dapat dimasukan kedalam body mesin, motor listrik yang telah terpasang pulley selanjutnya akan dihubungkan dengan pulley mixer (pengaduk) dengan menggunakan timing-blet (karet dynamo) mixer disini berfungsi sebagai pengaduk adonan, selanjutnya pulley mixer dihubungkan dengan pulley screw convayor dengan menggunakan timing belt juga, screw convayor berfungsi untuk mengantar dan memampatkan adonan ke moulding atau cetakan, yang selanjutnya adonan akan keluar sesuai cetakan yang terpasang.

Perancangan itu sendiri terdiri dari serangkaian kegiatan yang berurutan yaitu identifikasi suatu masalah dari kebutuhan masyarakat hingga penyelesaiannya. Maka dari itu perancangan disebut sebagai proses perancangan yang mencangkup seluruh kegiatan dalam perancangan seperti 


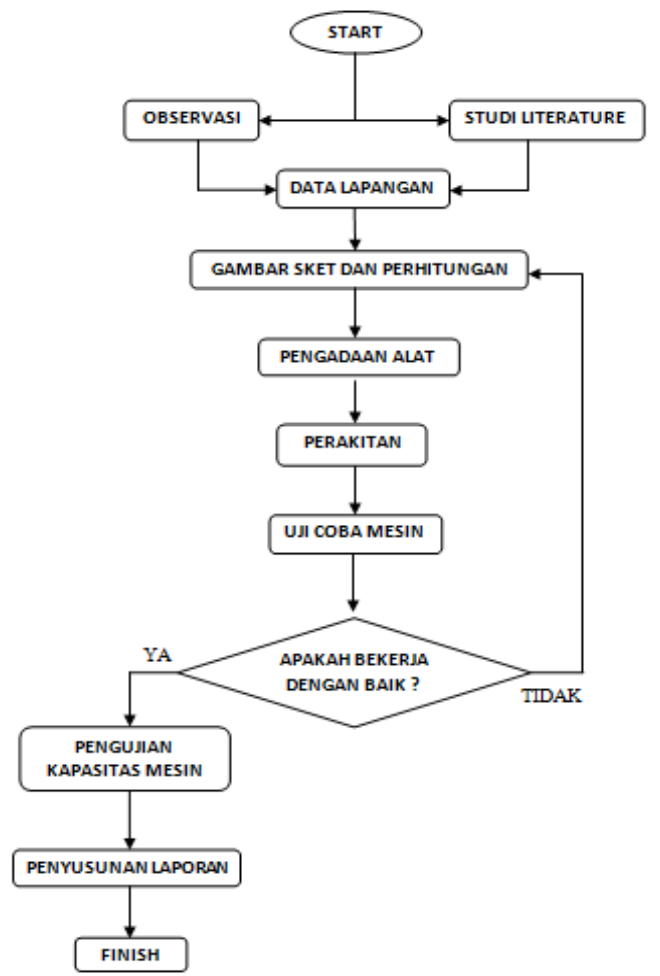

Gambar 1 Flow Chart Perancangan Kegiatan

\section{HASIL DAN PEMBAHASAN}

\section{Desain Mesin Pencetak Mie}

Seiring dengan bertambah majunya perkembangan di dunia teknologi sehingga mengubah pemikiran bagaimana caranya mengurangi beban kelelahan dalam pekerjaan yang sangat keras sehingga dapat mengerjakan beban yang sangat keras dan melelahkan dapat teratasi.Perhitungan dan perakitan bagian - bagian dari mesin Pencetak Mie ini disesuaikan dengan kapasitas dan daya motor sekaligus bahan yang sesuai dengan bahan yang terdapat dipasaran.

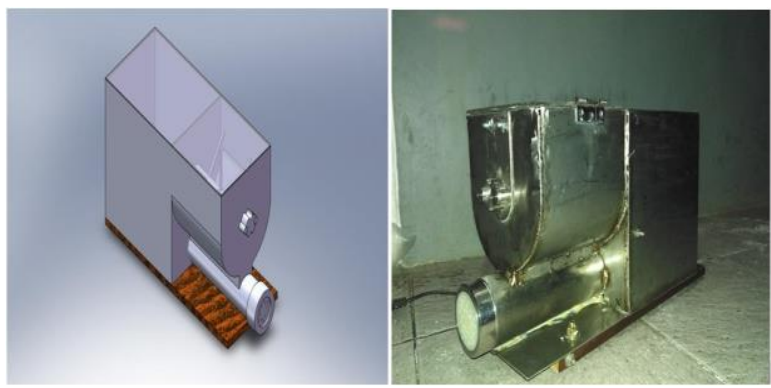

Gambar 2. Mesin Pencetak Mie
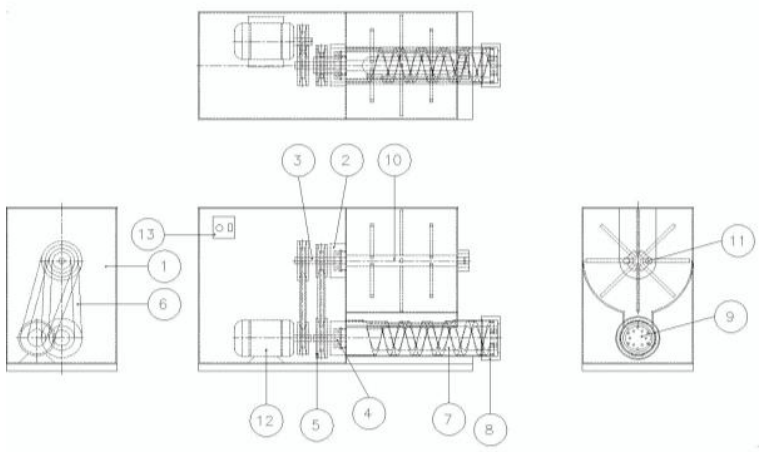

Gambar 3 Rangkaian Alat Pencetak Mie

Keterangan Gambar:

1. Rangka atau Body

2. Pillow block

3. Poros 1

4. Poros 2

5. Pulley

6. Sabuk (V-Belt)

7. Screw

8. Clamp

9. Mould

10. Mixer

11. Lock

12. Setelan sabuk

13. Saklar on/off

\section{Data-data Mekanisme Pencetak Mie}

Bagian - bagian utama dari rancang bangun ulang mesin pencetak mie, Antara lain :

1. Elemen yang berputar : puli, poros, bearing, mixer, screw conveyor, sabuk

2. Elemen yang diam : pipa screw, pillow block, cetakan, penahan mixer

3. Penggerak : motor listrik

4. Bagian utama : body mesin

\section{Data - data perencanaan:}

- Data motor : $0.37 \mathrm{Kw}, 1500 \mathrm{Rpm}, 50 \mathrm{~Hz}$

- Pcd Antara poros mixer dan screw conveyor : 108 $\mathrm{mm}$

- Pcd Antara poros mixer dan motor : $113 \mathrm{~mm}$

- Diameter poros motor : $12 \mathrm{~mm}$

- Diameter poros mixer dan screw conveyor :10 mm

- Diameter pulley motor $\left(D_{1}\right): 21 \mathrm{~mm}$

- Diameter pulley ganda poros mixer $\left(D_{2}\right): 42 \mathrm{~mm}$ dan $21 \mathrm{~mm}$

- Diameter pulley poros Screw convayor $\left(D_{3}\right): 45$ $\mathrm{mm}$

- Diameter poros mixer : $10 \mathrm{~mm}$

- Panjang mixer : $160 \mathrm{~mm}$

- Diameter screw conveyor : $54 \mathrm{~mm}$

- Panjang screw conveyor : $193 \mathrm{~mm}$

\section{Rangka Atau Body Mesin}

Rangka Atau Body mesin ini merupakan komponen yang harus ada pada mesin pencetak mie dikarenakan rangka Atau Body merupakan penompang komponen - komponen yang ada pada mesin pencetak mie. Konstruksi dari rangka mesin pencetak mie ini harus anti karat dan noda sekaligus kokoh .

Gambar 4. Rangka atau Body Mesin

\section{Perhitungan Kecepatan Pulley 1 (mixer)}

$\frac{D 2}{D 1}=\frac{n 1}{n 2}$

(elemen mesin, Ir.Jac STOLK; 1984; 345)

Dimana $\mathrm{n} 1=$ putaran poros motor listrik (rpm), $\mathrm{n} 2=$ putaran poros mixer (rpm), D1 = diameter puli motor listrik $(\mathrm{mm}), \mathrm{D} 2=$ diameter puli mixer $(\mathrm{mm})$ 
Menentukan Panjang Belt Motor ke Pulley Mixer

$L=2 C+\frac{\pi}{2}(d 2+d 1)+\frac{1}{4 C}(d 2-d 1)^{2}$

(Sularso dan kiyokatsu suga, 2004:170)

Dimana C = Jarak poros, D1 = Diameter pulley motor, D2

$=$ Diameter pulley mixer

\section{Menghitung kecepatan belt}

$\mathrm{V}=\frac{\pi \cdot \mathrm{d} \cdot \mathrm{n}}{1000 \times 60}$

(sularso dan kiyatsu suga,2004:166)

Dimana $\mathrm{V}=$ kecepatan sabuk, $\mathrm{d}=$ diameter puli, $\mathrm{n}=$ putaran motor

\section{Menentukan panjang belt mixer ke screw convayor}

$L=2 C+\frac{\pi}{2}(d 2+d 3)+\frac{1}{4 C}(d 3-d 2)^{2}$

(sularso dan kiyatsu suga,2004:166)

Dimana $C=$ jarak sumbu poros mixer ke screw conveyor, $\mathrm{D} 2=$ Diameter pulley mixer, D3 $=$ Diameter pulley screw convayor

\section{Proses Untuk Membuat Komponen Mesin Pencetak Mie}

\section{- Proses pemotongan}

Pemotongan adalah tahap pekerja pemotongan bahan baku profil dan plat baja sesuai dengan tanda potong yang telah ditetapkan pada proses penandaan. Prinsip kerja pemotongan seperti pada gambar berikut.

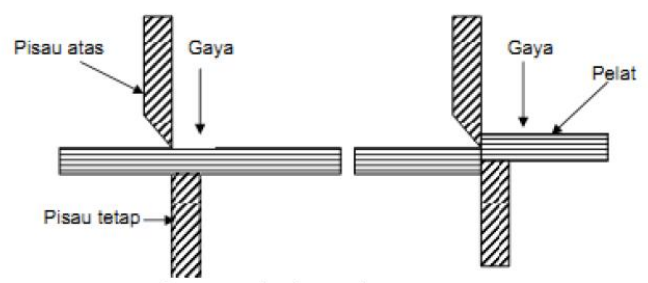

Gambar 5. Prinsip kerja pemotongan

\section{- Proses bengkok (Bending)}

Proses Bending adalah proses pembengkokan atau penekukan. Proses bending Plat adalah proses penekukan plat dengan alat bending baik manual maupun dengan menggunakan Mesin Bending. Dalam hal ini proses bengkok (bending) dilakukan untuk membuat body mesin. Material plat bisa dibending dengan menggunakan pisau bending dan dies.

Kecepatan potong mesin bubut dapat dihitung dengan menggunakan rumus. (Daryanto,2010)

$$
C S=\frac{d . \pi \cdot n}{1000}
$$

Keterangan :

$C S=$ Cutting Speed ( kecepatan potong ) dalam satuan meter/menit., $d=$ Diameter (garis tengah) benda kerja dalam satuan milimeter, $\pi=\frac{22}{7}=3,14, n=$ Putaran mesin per menit $(\mathrm{rpm}=$ revolution per minute)

Kecepatan putar mesin bubut dapat di hitung dengan menggunakan rumus. (Daryanto,2010)

$$
n=\frac{C S \times 1000}{\pi \cdot d}
$$

Keterangan :

$n=$ Putaran mesin permenit (rpm), CS = Cutting Speed ( kecepatan potong ) dalam satuan meter $/$ menit, $\pi=$ $\frac{22}{7}=3,14, d=$ Diameter (garis tengah) benda kerja dalam satuan milimeter.

\section{- Proses pengelasan listrik}

Las listrik adalah salah satu cara menyambung logam dengan jalan menggunakan nyala busur listrik yang diarahkan ke permukaan logam yang akan disambung.

\section{- Proses pembubutan}

Proses pembubutan adalah salah satu proses pemesinan yang menggunakan pahat dengan satu mata potong untuk membuang material dari permukaan benda kerja yang berputar.

\section{- Proses pengefraisan}

Proses pengefraisan (Milling) adalah proses yang menghasilkan chips (beram), Milling menghasilkan permukaan yang datar atau berbentuk profil pada ukuran yang ditentukan dan kehalusan atau kualitas permukaan yang ditentukan.

\section{- Proses pengeboran}

Mesin bor umumnya digunakan untuk mengebor lubang-lubang yang berdiameter kecil sampai diameter besar. Kepala mesin dapat digerakkan ke atas dan ke bawah sepanjang tiang yang terpasang di meja kerja (alas). Penggerak mesin berupa motor listrik yang dapat memutarkan poros dengan sabuk pemutar (belt). Poros berputar di dalam rumah pipa (drill sleeve) yang mana dapat digerakkan ke atas dan kebawah dengan bantuan dari roda gigi dan balok bergigi. Roda gigi berputar dengan tuas pemutar yang menghasilkan tekanan pemakan bagi alat potongnya.

\section{Teori Dasar Perhitungan Komponen Mesin} Pencetak Mie

Teori dasar perhitungan merupakan suatu dasar untuk menentukan suatu komponen supaya memenuhi standart. Maka dari itu untuk membuat suatu komponen mesin pencetak mie diperlukan teori dasar perhitungan penunjang sebagai berikut:

\section{Poros (shaft)}

Shaft (poros) adalah elemen mesin yang digunakan untuk mentransmisikan daya dari satu tempat ke tempat lainnya. Daya tersebut dihasilkan oleh gaya tangensial dan momen torsi yang hasil akhirnya adalah daya tersebut akan ditransmisikan kepada elemen lain yang berhubungan dengan poros tersebut. Poros juga merupakan suatu bagian stasioner yang beputar, biasanya berpenampang bulat dimana terpasang elemen-elemen seperti roda gigi (gear), pulley, flywheel, engkol, sprocket dan elemen pemindah lainnya. Poros bisa menerima beban lenturan, beban tarikan, beban tekan atau beban puntiran yang bekerja sendiri-sendiri atau berupa gabungan satu dengan lainnya. 


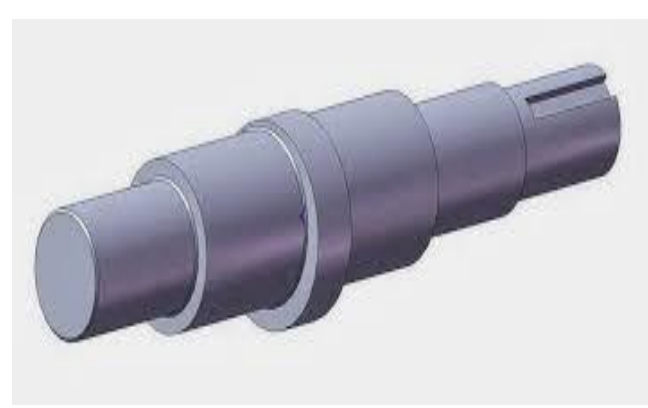

Gambar 6. Poros

\section{- Perhitungan poros}

a. Rumus perhitungan daya (daya rencana) $\mathrm{Pd}=\mathrm{Fc}$. $\mathrm{P}$

Dimana $\mathrm{Pd}=$ daya rencana $(\mathrm{kW}), \mathrm{Fc}=$ Faktor koreksi, $\mathrm{P}=$ daya nominal output darimotor penggerak $(\mathrm{kW})$

b. Moment puntir ( Torsi)

$$
\mathrm{T}=9,75 \times 10^{5} \frac{P d}{n 1}
$$

Dimana $\mathrm{T}=$ moment puntir (N.mm), n1= putaran motor penggerak $(\mathrm{Rpm}), \mathrm{Pd}=$ daya rencana $(\mathrm{kW})$

c. Tegangan geser

$\tau_{\alpha}=\sigma_{\mathrm{b}} /\left(\mathrm{Sf}_{1} \times \mathrm{Sf}_{2}\right)$

Dengan : $\tau_{\alpha}=$ Tegangan Geser $(\mathrm{Kg} / \mathrm{mm} 3), \sigma_{\mathrm{b}}=$ kekuatan Tarik (Kg/mm3), Sf ${ }_{1}$ Faktor keamanan, $\mathrm{Sf}_{2}=$ Faktor keamanan

\section{- Pulley}

Pulley merupakan salah satu elemen dalam mesin yang berfungsi sebagai alat yang meneruskan daya dari satu poros ke poros yang lain dengan menggunakan sabuk.

\section{- $\quad$ Poros 1}

Poros 1 merupakan salah satu komponen mesin yang berbentuk silindris memanjang dengan penampang yang biasanya berbentuk lingkaran yang memiliki fungsi sebagai penyalur daya atau tenaga melalui putaran sehingga poros ikut berputar dan menggerakkan Mixer.

\section{- $\quad$ Sabuk V (V-Belt)}

Sabuk V (V-belt) adalah suatu elemen flexible yang dapat digunakan dengan mudah mentransmisi torsi dan gerakan berputar dari suatu komponen ke komponen lainya, dimana belt tersebut dililitkan pada puli yang melekat pada poros yang akan berputar.

\section{- Screw}

Screw merupakan komponen mesin yang berfungsi untuk memindahkan atau mentransfer adonan mie kedalam cetakan ( Mould) mie.

\section{- Bantalan (Bearing)}

Menurut Elemen mesin, Sularso,1987,hal

103, Bantalan adalah elemen mesin yang menumpu poros berbeban, sehingga putaran atau gerakan bolakbaliknya dapat berlangsung secara halus, aman dan panjang umur.

\section{- Pasak}

Pasak merupakan sebagian dari mesin yang penggunaanya berfungsi sebagai penyambung yang digunakan untuk menjaga hubungan putaran relative
Antara poros dari mesin yang lain seperti roda gigi, puli, suprocket dan lain sebagainya.

Moment rencana dari poros :

$$
F=\frac{T}{\left(\frac{D S}{2}\right)}
$$

(sularo,kiyokatsu suga ;1978)

Dimana $\mathrm{F}$ = gaya tangensial $(\mathrm{kg}), \mathrm{T}=$ moment rencana (kg.mm), Ds = diameter poros

Gaya geser yang bekerja:

$$
\tau k \frac{F}{b . l}
$$

(sularo,kiyokatsu suga ;1978)

Dimana $\tau=$ Tegangan geser $\left(\mathrm{kg} / \mathrm{mm}^{2}\right), \quad F=$ Gaya tangensial (Kg), B = Lebar, L = Panjang

\section{- Screw convayor}

Screw conveyor berfungsi intuk mengantarkan dan memanpatkan adonan ke cetakan, prinsip kerjanya sama dengan prinsip kerja dari ulir pada mur dan baut yaitu mengubah gaya radial menjadi gaya aksial yang sifatnya mendorong atau menarik mur sebagai pasanganya sesuai dengan arah putarannya, scre conveyor dapat dilihat pada gambar dibawah ini

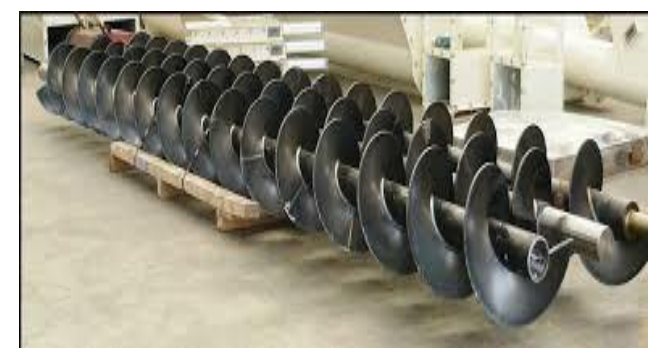

Gambar 7. Screw conveyor

Kapasitas dari screw conveyor tergantung dari diameter, screw pitch, putaran dan efisiensi daerah vertical screw.

$$
\begin{aligned}
& \frac{C}{R p m}=\frac{0,7854(d s 2-d p 2) P . K .60}{1728} \\
& \text { (CEMA-screw conveyor, 1971:25) }
\end{aligned}
$$

Dimana $\mathrm{C}$ = kapasitas volume screw conveyor $(\mathrm{Kg} / \mathrm{jam})$, Ds $=$ diameter screw conveyor $(\mathrm{cm}), \mathrm{Dp}=$ diameter pipa $(\mathrm{cm}), \mathrm{P}=$ pitch dari screw conveyor $(\mathrm{cm}), \mathrm{K}=$ prosentase dari pembebanan tabung (\%)

Kecepatan screw conveyor dapat dihitung dengan rumus (CEMA-screw conveyor, 1971:25) :

$$
N=\frac{\text { kapasitas yang direncanakan }(C)}{V p \times k \times 60}
$$

Dimana $\mathrm{N}=$ kecepatan dari ulir (rpm) (N tidak boleh lebih dari kecepatan maksimum yang dianjurkan), $\mathrm{C}=$ kapasitas $(\mathrm{kg} / \mathrm{jam}), \mathrm{K}=$ prosentase kapasitas yang dialirkan (\%)

Perhitungan daya untuk memutar screw conveyor Daya yang dibutuhkan addalah daya total dari gesekan conveyor $\left(\mathrm{HP}_{\mathrm{f}}\right)$ dan daya untuk memindahkan matrial pada ukuran tertentu $\left(\mathrm{HP}_{\mathrm{m}}\right)$ dikalikan dengan faktor beban lebih (FO) dan dibagi efisiensi penggerak total (e). 


$$
\mathrm{HPf}=\frac{L s . N \cdot F d \cdot F b}{1000000}
$$

(CEMA-screw conveyor 1971:36)

Dimana $\mathrm{Hp}_{\mathrm{f}}=$ daya total karena gesekan conveyor (HP), $\mathrm{L}=$ panjang dari conveyor $(\mathrm{mm}), \mathrm{N}=$ kecepatan screw conveyor (rpm), $\mathrm{Fd}=$ diameter conveyor factor, $\mathrm{Fb}=$ hanger bearing factor

$$
\mathrm{HPm}=\frac{C . L s . W \cdot F r . F m \cdot F p}{1000000}
$$

(CEMA-screw conveyor 1971:36)

Dimana $\mathrm{Hp}_{\mathrm{m}}=$ daya untuk memindahkan matrial (HP), C = kapasitas screw conveyor $(\mathrm{kg} / \mathrm{jam}), \mathrm{W}=$ berat jenis matrial, $F_{r}=$ faktor jarak, $F_{m}=$ faktor matrial, $F_{p}=$ Faktor suhu

Berdasarkan pengaruh terhadap daya tersebut, maka daya maksimum yang dibutuhkan screw conveyor (Hptotal) dapat dihitung dengan persamaan :

$$
\mathrm{HP}_{\text {total }}=\frac{(H p p+H p m) \cdot F b l}{e}
$$

(CEMA-screw conveyor 1971:36)

Dimana $\mathrm{Hp}_{\mathrm{m}}$ = daya untuk memindahkan matrial (HP), $\mathrm{Hp}_{\mathrm{f}}=$ daya total karena gesekan conveyor (HP), Fbl = Faktor beban lebih, $\mathrm{E}=$ efisien penggerak

\section{- Motor Elektrik (AC)}

Motor elektrik berfungsi sebagai tenaga penggerak yang digunakan untuk memutar puli pada mixer dan juga puli pada screw. Penggunaan motor elektrik disesuaikan dengan kebutuhan daya mesin yang diperlukan untuk proses mengaduk adonan dan mencetak adonan.

Jika $n_{1}(\mathrm{rpm})$ adalah putaran dari poros motor listrik dan T (Kg.mm) adalah torsi pada poros motor listrik, maka besarnya daya $\mathrm{P}(\mathrm{kW})$ yang diperlukan untuk menggerakan system adalah :

$$
P=\frac{T}{9.74 \times 10^{5}} n_{1}
$$

Dimana $\mathrm{P}=$ daya motor listrik $(\mathrm{kW}), \mathrm{T}=$ Torsi (Kg.mm), $n_{1}=$ putaran motor penggerak (rpm)

\section{PENUTUP}

Dari hasil dan pembahasan sebelumnya maka diperoleh daya yang dibutuhkan oleh mesin pencetak mie sebesar 0,3 Kw. Belt yang digunakan adalah jenis Vbelt type $A($ lebar(b)=13 mm), tinggi $(\mathrm{h})=8 \mathrm{~mm}$, dengan Panjang belt 12" dan 13". Jumlah belt 2 buah. Screw yang digunkan adalah screw horizontal standard dengan bahan P.E dan kapasitas conveyor loading 15\%. Kapasitas rata-rata mesin pencetak mie ini adalah 0,66 $\mathrm{kg} /$ menit.

Perancangan desain mesin yang cukup sederhana (dan tidak menutup kemungkinan pada bagian lain ) perlu dipertimbangkan lebih dalam. Dalam proses pembuatan dimungkinkan juga melewati tahap mencoba coba atau trial and error. Pertimbangan ekonomis agar biaya pembuatan mesin menjadi murah hendaknya tidak membatasi kreasi dan inovasi perancangan. Sehingga dengan biaya yang sedikit mungkin, tetap dapat menciptakan mesin yang lebih berkualitas.

Dalam hal ini penulisan jurnal ini masih dapat dikembangkan lagi sehingga diharapkan dapat memperbaiki kekurangan yang ada di jurnal ini. Sehingga dapat menghadirkan alat yang lebih canggih lagi.

\section{DAFTAR PUSTAKA}

Daryanto. (2010). Teori Kejuruan Mesin Perkakas. Satu Nusa.

Mairizal. (2011). Perencanaan dan Transmisi Daya Mesin Pencetak Mie. Gunadarma. Jawa Barat.

http://library.gunadarma.ac.id/repository/ view/15565/perencanaan-dan-transmisidaya-mesin-pencetak-mie.html/

Rochim, T. (2007). Klarifikasi Proses, Gaya, dan Daya Pemesinan. Bandung : ITB

Stolk, Ir. Jac. \& Kros Ir. C. (1984). Elemen Mesin, Elemen Konstruksi dari Bangunan Mesin. Erlangga: Jakarta Barat.

Sutarjo. (1997). Petunjuk Praktek Las Acetylene dan Listrik. (Jilid I). Surabaya

Taufiq Rochim. (2007). Klasifikasi Proses, Gaya \& Daya Pemesinan. Bandung : ITB 
AM Hidayatullah / Mechonversio, Vol. 1, No.1, Desember 2018, 28-33

Halaman ini sengaja dikosongkan 